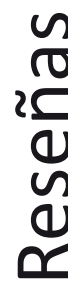

\title{
The Ethics of Peacebuilding
}

\section{Tim Murithi}

Edimburgo, Edimburgh University Press, Edimburgh Studies

in World Ethics, 2009, 188 pp

La consolidación de la paz o "peacebuilding» se ha convertido en los últimos años en uno de los cometidos más importantes y trascendentales de las Naciones Unidas en la resolución de conflictos, y es muy probable que crezca su importancia para el siglo XXI, como se puede ver de los esfuerzos en darle forma institucional mediante la creación de la Comisión de Consolidación de la Paz (CCP). El término «consolidación de la paz» tuvo su aparición a principios de la década de los años noventa en las Naciones Unidas, cuando el Secretario General Boutros Boutros-Ghali, en su famoso informe «Un programa de paz», la incluyó dentro de las tareas centrales de la Organización de las Naciones Unidas para el mantenimiento de la paz destinadas a asistir a Estados que salían de un conflicto militar interno y requerirían de la ayuda internacional para su reconstrucción.

De este tema trata precisamente el libro que nos ocupa, el cual no se dedica simplemente a analizar la consolidación de la paz desde la práctica de las Naciones Unidas para después dar consejos «técnicos» de su efectividad, como lo hace una buena mayoría de autores en esta materia, sino va mucho más allá de este parámetro. Se ocupa de aspectos más trascedentales que consisten, sobre todo, en la fijación de presupuestos morales de la consolidación de la paz para, a partir de ellos, valorar su práctica actual. Pero el mayor valor de esta obra se encuentra en la propuesta abierta de un modelo de consolidación de la paz basado en la moral, que sirve de plataforma para canalizar su práctica actual por la vía de la moralidad. Es así que el 
lector no encontrará en esta obra crítica alguna de la idea de la consolidación de la paz en sí, sino solo del modo en que es puesta actualmente en práctica.

De forma sencilla y metódica el autor desarrolla su esquema ético de consolidación de la paz, que apunta a lograr una mayor efectividad y sostenibilidad a largo plazo. Su concepción de ella es amplia, en el sentido de que la entiende como un proceso de construcción política, social, económica y de seguridad de una sociedad que emerge de un conflicto. En esta concepción están implícitos un concepto positivo de paz, que exige a su vez procesos de curación y reconciliación así como un concepto amplio de justicia, que sea restaurativa y fomente la igualdad social y económica. En cuanto a la conexión entre paz y justicia, el autor destaca la importancia de su interrelación puesto que la construcción de la paz requiere también la promoción de la justicia económica y social. Lo sobresaliente en la obra - a diferencia de publicaciones similares que se concentran en la víctima- es su enfoque tridimensional en víctimas, perpetradores e intermediarios, quienes están presentes a lo largo de sus reflexiones.

Su visión ética de la consolidación de la paz es tan consecuente como para penetrar en los subprocesos de negociación, mediación, perdón y reconciliación, que desarrolla con bastante nitidez y con la profundidad necesaria para entender su importancia. Su exposición está distribuida en 8 capítulos. El primero hace de introducción y en él se resaltan los puntos cruciales de la tesis del autor y se presentan el contenido y estructura del libro. El capítulo segundo contiene el fondo filosófico del autor quien, basado en la existencia del conocimiento moral y apoyado en una visión cosmopolita de la paz, sostiene el valor ético intrínseco del estudio de la consolidación de la paz, oponiéndose así a posiciones contrarias como el realismo político y el positivismo. En el tercer capítulo entra en el análisis de los conflictos subnacionales o civiles, revelando las limitaciones de los mecanismos actuales de resolución de conflictos, que están centrados en el Estado y se orientan políticas de exclusión. Propone conceder un estatus de interlocutor igualitario a grupos o comunidades, a fin de que estos también estén inmersos en los procesos de resolución de conflictos y consolidación de la paz. El capítu- 
lo cuarto trata de los procesos de negociación y mediación como elementos éticos imprescindibles para alcanzar la paz. Por ser la mediación la práctica más usual en la resolución de conflictos, le otorga amplio espacio. Así, el autor la entiende como un proceso ético que debe usar el consenso antes que la coacción, la infuencia, la manipulación y la sanción. Utiliza el ejemplo de la Liga de Naciones e iniciativas privadas como la de los Quakers. El capítulo quinto se centra en el proceso del perdón como virtud de las víctimas para aceptar la inclusión moral de los perpetradores en el proceso de consolidación de la paz. Como su autor lo reconoce, se trata de una de las tareas más difíciles y menos desarrolladas de la consolidación de la paz. En el capítulo sexto se trata la reconciliación como un proceso en que están necesariamente interconectadas la paz y la justicia, esta última debiendo entenderse como restaurativa y no retributiva, como ocurre en la práctica general. A manera de ejemplos se citan las Comisiones de la Verdad y Reconciliación de Sierra Leona y Sudáfrica, y tradiciones éticas locales como la idea del Ubuntu en comunidades de África Central y del Sur. El autor es crítico frente a la justicia punitiva o retributiva (castigo a los perpetradores) que a su juicio solo genera un clima de desconfianza, sospecha y resentimiento y trae como consecuencia la exclusión. Sin embargo, esta crítica queda corta puesto que se refiere muy escuetamente al trabajo de los tribunales penales internacionales. El capítulo séptimo es reservado a la propuesta de un programa práctico de promoción de la consolidación ética de la paz y destaca una vez más el carácter moral de las disputas subnacionales y tiene presentes los esfuerzos recientes de consolidación de la paz a nivel de las Naciones Unidas. Aquí el autor tampoco se extiende en su proposición de transformar las normas internacionales y crear un modelo alternativo al sistema de Estados. El último capítulo sella la exposición con una recapitulación de los puntos principales tratados a lo largo de la obra.

Los puntos discutibles de la obra, que radican en su fundamentación filosófica y el supuesto resultante de que el sistema westfaliano de Estados con su principio de soberanía constituirían un impedimento al programa de paz ética, no pesan frente a su contribución valiosa para el estudio de la consolidación de la paz en una dimensión mucho más amplia que las hechas 
hasta ahora sobre el tema. Otro aspecto trascendental de la obra es su perspectiva pacifista o no violenta, que sin caer en dogmas pacifistas es transmitida de hecho en cada uno de los procesos de consolidación de la paz que propone.

Podríamos concordar con el autor en que es preciso poner en práctica una dimensión ética amplia de la consolidación de la paz, la que se deberá aplicar a nivel local, gubernamental e internacional para ayudar a sociedades a recuperarse después de un conflicto y su obra es quizás la propuesta más acabada y más razonable para lograrlo.

$M^{a}$ Cecilia Añaños 